\title{
Biologically active organic compounds as insect growth regulators (IGRs): introduction, mode of action, and some synthetic methods
}

\author{
Mohamed A. Gad ${ }^{a *}$, Safwat A. Aref ${ }^{\mathrm{a}}$, Antar A. Abdelhamid ${ }^{\mathrm{b}}$, M. M. Elwassimy ${ }^{\mathrm{b}}$ and Shaban A. A. \\ Abdel-Raheem ${ }^{c}$
}

${ }^{a}$ Research Institute of Plant Protection, Agriculture Research Center, 12112 Giza, Egypt

${ }^{b}$ Department of Chemistry, Faculty of Science, Sohag University, 82524 Sohag, Egypt

${ }^{c}$ Soil, Water, and Environment Research Institute, Agriculture Research Center, Giza, Egypt

\section{H R O N I C L E}

Article history:

Received January 29, 2021

Received in revised form

April 11, 2021

Accepted May 31, 2021

Available online

May 31, 2021

Keywords:

Growth regulators

Synthesis

Mode of action

Insects

\section{Introduction}

There is no doubt that there are many organic compounds with good biological and pharmacological activities. ${ }^{1-15}$ Insect growth regulators (IGRs), also called third-generation insecticides, are pesticides that disrupt the normal activity of the endocrine or hormone system of the insects, affecting the development, reproduction, or metamorphosis of the target insect. ${ }^{16}$ Several features of insect growth regulators (IGRs) make them attractive as alternatives to broad-spectrum insecticides. ${ }^{17}$ Some of these features are more selective, less harmful to the environment, more compatible with pest management systems that include biological control, ${ }^{18}$ and less likely to be lost because of resistance. Insects have demonstrated a propensity to develop resistance to insecticides. ${ }^{19}$ Virtually all chemicals used to control insects fall into one of three categories: neurotoxins, growth regulators and behavior modifiers.Most chemicals used to control insects are neurotoxins which interfere with normal nerve function. Organophosphorus insecticides were derived from nerve gases that were first exploited for military purposes. Other insecticides were discovered by testing chemicals to find their insecticidal activities. ${ }^{20}$ Among those that kill quickly is a neurotoxin acted on neurotransmissions was sought and developed as an insecticide. In the early discovery and development of insecticides, efforts were focused on chemistry rather than biology. ${ }^{21}$ Insect growth regulators (IGRs) are compounds that interfere with * Corresponding author.

E-mail address: samy adjey@yahoo.com (M. A. Gad)

(C) 2021 by the authors; licensee Growing Science, Canada doi: $10.5267 /$ j.ccl.2021.005.004 
insect-specific physiological systems that do not exist in vertebrates. ${ }^{22}$ A hard cuticle, serving as an exoskeleton, covers the body of insects and related arthropods. Once produced, the cuticle cannot grow; to allow growing of the insect, the old cuticle is shed and a new, larger, and often different cuticle is formed. ${ }^{23}$ This change of the cuticle is termed molt or molting and a stage between two consecutive molts is named an "instar." To reach the adult stage, insects molt several times, i.e., they have several instars, and they undergo "metamorphosis" from larva or nymph to adult, or from larva to pupa and then from pupa to adult. ${ }^{24}$ Both molting and metamorphosis are regulated by hormones secreted by endocrine organs. These physiological systems are not shared by vertebrates, or differ from vertebrate systems, and they constitute targets to IGRs. Most IGRs used today in insect control either interfere with the formation of the new cuticle or disturb metamorphosis. ${ }^{25}$ IGRs deregulate rather than regulate insect development; therefore, the recently (though yet infrequently) used term "Insect Development Inhibitors" is more suitable. ${ }^{26}$

\section{Discovery of Insect growth regulators}

The first account of the potential use of IGRs in insect control was in 1956, when juvenile hormone $(\mathrm{JH})$ was isolated from the abdominal crude extract of the male Cecropia moths Hyalophoracecropia (L.). ${ }^{27}$ Topical application of the hormone prevented metamorphosis and subsequent multiplication of the insect. However, it was not observed until the discovery of the Paper factor in 1965 because the paper factor led to an understanding of the potential use of $\mathrm{JH}$ in insect development. Researchers at Harvard observed that cultures of the linden bug, Pyrrhocorisapterus L., which originally came from Czechoslovakia, had low egg hatch rates and those supernumerary larvae, rather than adults, were formed. The active component of the paper towel, which was later identified as juvabione, came from the balsam fir, Abisbalsamea (L.), the main pulp tree used in the United States paper industry (newspapers, magazines, etc.). Juvabione is a methyl ester of domatuic acid proven to be a very specific juvenile hormone mimic of the hemipteran family Pyrrhocoridae. The discovery of this highly specific substance led to industrial interests in JH as a tool in developing IGRs. ${ }^{28}$ The origin of IGRs was entirely different. Their discovery was based on the knowledge of how insects grow, develop, function and behave. ${ }^{29}$ They have been discovered in two ways one way was to expose an insect to IGRs and observe abnormalities in how it develops functions or behaves. Chemicals that produce desired effects were developed. Another way to find out what processes in the insects' development involves, hormones and to use those hormones as models to synthesize chemical analogs that will interfere with normal insect growth and development. Because IGRs act on systems unique to insects, or shared with close relatives, they are less likely to affect other organisms. ${ }^{30}$ In 1967 Carrol Williams proposed that the term " third generation pesticide" "can be applied to the potential use of the insect juvenile hormone (JH) as an insecticide, and suggested that it would not only be environmentally benign but that the pest insects would also be unable to develop resistance. However, it took several years before the first commercial juvenile hormone analog (JHA) made its debut. ${ }^{31,32}$ After that, several compounds that adversely interfere with the growth and development of insects have been synthesized, and have been collectively referred to as insect growth regulators (IGRs). ${ }^{33}$ Concerns over eco-toxicology and mammalian safety have resulted in a paradigm shift from the development of neurotoxic, broad-spectrum insecticides towards softer, more environmentally friendly pest control agents such as IGRs. This search has led to the discovery of chemicals that interfere with physiological and biochemical systems that are unique to either insect in particular or arthropods, in general, have insect specific toxicity based on either molecular target site or vulnerability to a development stage and are safe to the environment and nontarget species. The rationale was that if the pest insect is treated with a chemical analog, which mimics the action of hormones like JHs and ecdysteroids, at an inappropriate stage the hormonal imbalance would force the insect to go through abnormal development leading to mortality. It was also thought that because such chemicals would in many instances work via the receptor(s) of these hormones, it was less likely for the affected population to develop target site resistance. Yet other target sites are the biosynthetic steps of cuticle formation, which insects share with other arthropods. Adversely interfering with this process would result in the inability of the intoxicated insect to molt and undergo further 
development. Unlike neurotoxic insecticides that are fast-acting, IGRs are in general slow-acting, which might result in more damage to the crop. However, some IGRs, such as ecdysone agonists, induce feeding inhibition, significantly reducing the damage to below acceptable levels. The slow mode of action of some IGRs, such as chitin synthesis inhibitors, can be an advantage in controlling social insects, such as termites, where the material has to be carried to the brood and spread to other members.

It was in the early seventies that the first chitin synthesis inhibitor, a benzoylphenylurea, was discovered by scientists at Philips Duphar BV, and marketed as dimilin by the Uniroyal Chemical Company (Crompton Corp. Middlebury, CT) in the USA. Since then, several new analogs that interfere with one or more steps of cuticle synthesis have been synthesized and are being marketed for controlling various pests. With an emphasis on after the initial success with the synthesis of methoprene by Zoecon (Palo Alto, CA, USA) very few new JHAs with good control potential other than pyriproxyfen and fenoxycarb have been developed. These compounds have been particularly useful in targeting the eggs and embryonic development as well as larvae. The synthesis of pyriproxyfen and fenoxycarb was a departure from the terpenoid structure of JHs and earlier JHAs. Early attempts in the 1970s to synthesize insecticides with molting hormone (20-hydroxyecdysone) activity failed because they were based on a cholesterol backbone, which resulted in chemical and metabolic instability of the steroid nucleus. ${ }^{34}$ It took nearly two more decades before the first nonsteroidal ecdysone agonist, based on the bisacylhydrazine class of compounds, was synthesized. ${ }^{35}$ Structure-activity optimization of the first such compound over the subsequent few years led to the synthesis of four highly effective compounds that have since been commercialized.

\section{How insect growth regulators work}

Insects wear their skeletons on the outside and these skeletons are called exoskeletons. As the insect grows, a new exoskeleton must be formed inside the old exoskeleton and the old one shed. The new one then swells to a larger size and hardens. ${ }^{36}$ The process is called molting. The changes from larval to adult form, this process is called metamorphosis, also take place during molting. Hormones control the phases of molting by acting on the epidermis that is part of the exoskeleton. ${ }^{37}$

\subsection{Mode of Action of the Insect Molting Hormone}

\subsubsection{Physiological Role}

Amongst the animal kingdom, arthropods display a remarkable adaptability and diversity in inhabiting very different ecological niches. Between larval and adult stages of a given insect, an insect undergoes distinct developmental and morphological changes that help it to survive in different environments. For example, mosquito larvae are perfectly suited to surviving in an aqueous environment, whereas the adult mosquitos inhabit terrestrial and aerial environments. Larval or nymphal stages of most of the agricultural pests develop on host plant species, and the adult assumes an aerial space to look for food and a mate, returning to the host plant only to oviposit and start another life cycle. The growth and development from one stage to another is regulated by two main hormones; the steroidal insect molting hormone, 20-hydroxyecdysone (Fig. 1) and the sesquiterpenoid JH, of which there are five types. Even as an insect embryo grows, it undergoes embryonic molts, where each molt is regulated by $20 \mathrm{E}$. The molting process continues through the larval and pupal stages culminating in the adult stage. The molting process is initiated by an increase in the titer of $20 \mathrm{E}$, and is completed following its decline and the release of eclosion hormone. In preparation for a molt and as the 20E titers increase, the larva stops feeding and apolysis of the epidermis from the old cuticle takes place leaving an ecdysial space that is filled with molting fluid containing inactive chitinolytic enzymes. During this time, the epidermal cells also reorganize in order that large quantities of protein can be synthesized for deposition of a happens with up and down regulation of a number of genes encoding a number of epidermal proteins and enzymes. ${ }^{38}$ The fall in the $20 \mathrm{E}$ titer triggers the activation of enzymes in the molting fluid for digestion of the procuticle underlying the old cuticle. This event is followed by the 
resorption of the molting fluid and preparation for ecdysis. ${ }^{38}$ When the $20 \mathrm{E}$ titer is cleared from the system, the eclosion hormone is released, which in turn results in the release of the ecdysis-triggering hormone, and all these events lead to the ecdysis of the larva leaving behind there mnants of the old cuticle. ${ }^{39,40}$ With the completion of ecdysis, feeding resumes and endocuticular deposition continues during the inter molt period.

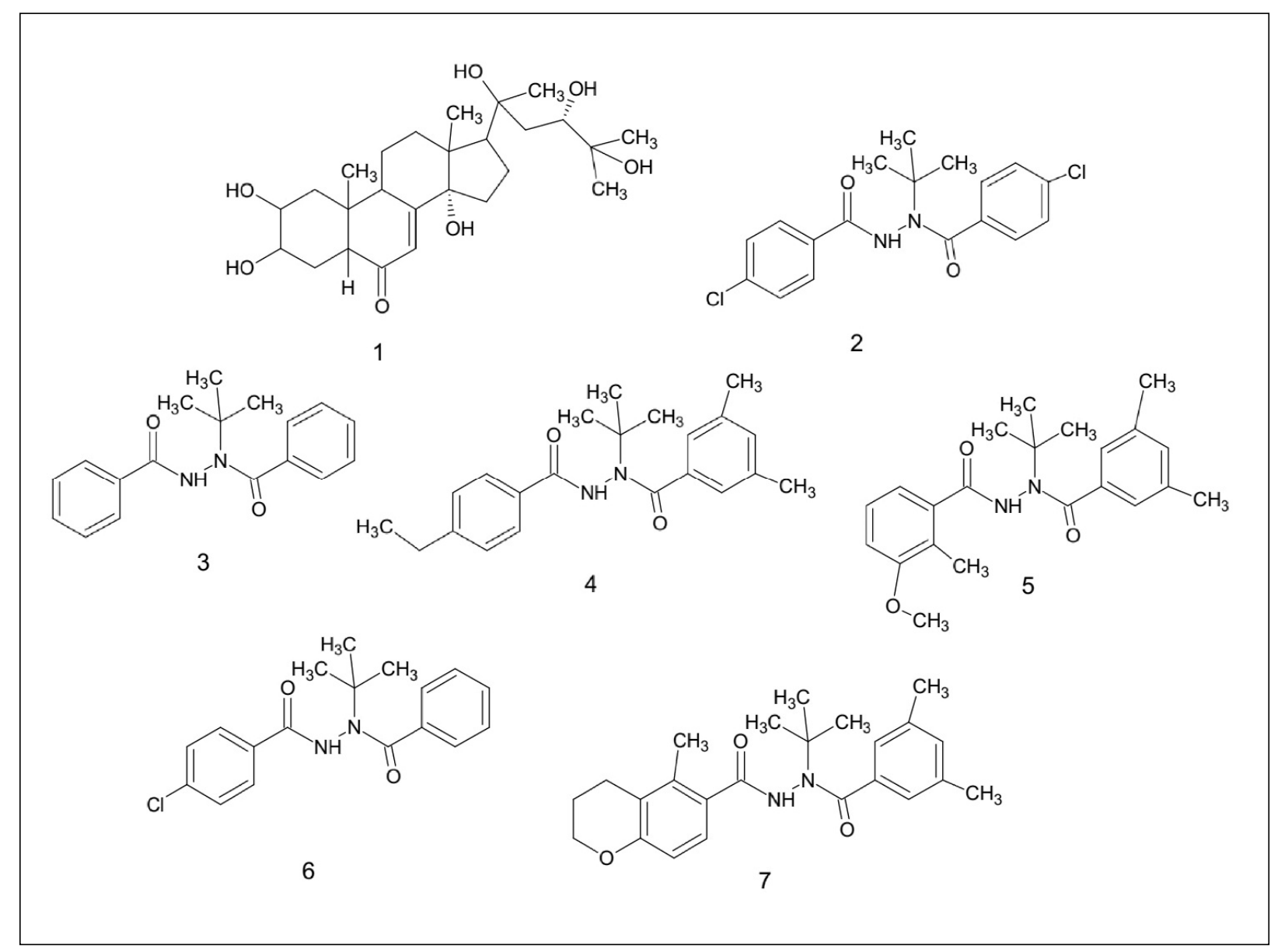

Fig. 1. Chemical structures of 20-hydroxyecdysone (1), the first discovered symmetrically substituted dichloro-dibenzoylhydrazine (2), RH-5849 (3), tebu-fenozide (4), methoxyfenozide (5), halofenozide (6), and chromofenozide (7).

\subsubsection{Ecdysteroid Agonist Insecticides}

\subsubsection{Discovery of Ecdysone Agonist Insecticides and Commercial Products}

Although attempts for discover insecticides with an insect molting hormone activity were made in the early $1970 \mathrm{~s},{ }^{41}$ it was not until a decade later that the first bisacylhydrazine ecdysone agonist (Fig. 1) was serendipitously discovered at Rohm and Haas Company, Springs House, PA, USA. ${ }^{35}$ Several years later, after several chemical iterations of this early lead, a simpler, unsubstituted, but slightly more potent analog, RH-5849 (Fig. 1), was discovered. ${ }^{42}$ Further work on the structure and activity of RH5849 resulted in more potent and cost-effective bisacyl hydrazines with a high degree of selective pest toxicity. ${ }^{43}$ Of these, three bisacylhydrazine compounds, all substituted analogs of RH-5849, coded as RH-5992 (tebufenozide (4); Fig. 1), RH-2485 (methoxyfenozide (5); Fig. 1), and RH-0345 (halofenozide (6); Fig. 1) have been commercialized (Table 1). Both tebufenozide and methoxy fenozideare selectively toxic to lepidopteran larvae. ${ }^{35}$ However, methoxyfenozide is more potent than tebufenozide, and is toxic to a wider range of lepidopteran pests of cotton, corn, and other agronomic 
pests. ${ }^{44}$ Halofenozide has a broader and an overall insect control spectrum somewhat similar to that of RH-5849, but with significantly higher oil-systemic efficacy against scarabid beetle larvae, cutworms, and webworms.

Another bisacylhydrazine, chromafenozide (7) coded as ANS-118; Fig. 1) was discovered and developed jointly by Nippon Kayaku Co., Ltd., Saitama, Japan and Sankyo Co., Ltd. Ibaraki, Japan. ${ }^{45}$ Chromafenozide, registered under the trade names, MATRIC and KILLAT, is commercialized for the control of lepidopteran larval pests of vegetables, fruits, vines, tea, rice, and ornamentals in Japan. ${ }^{46}$

Table 1. Bisacylhydrazine insecticides with edysone mode of action

$\begin{array}{lllll}\text { Structure } & \text { Common name } & \text { Code as industry } & \text { Registered name } & \text { Pest spectrum }\end{array}$

MIMIC,
CONFIRM,
ROMDAN

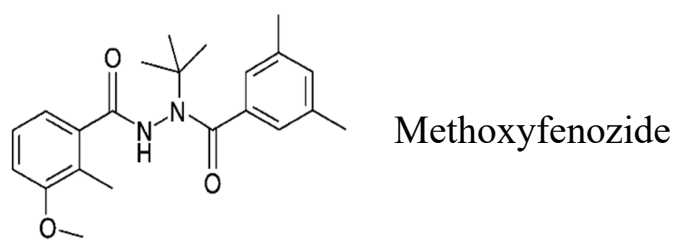

INTREPID,

RH2485

RUNNER,

PRODIGY,

lepidoptera

FALCON

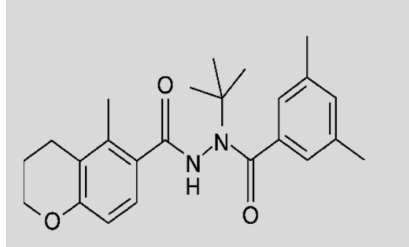

Chromofenozide

ANS118,

MATRIC, CM001 KILLAT

lepidoptera<smiles>CC(C)(C)N(NC(=O)c1ccc(Cl)cc1)C(=O)c1ccccc1</smiles>

Halofenozide

RH-0345

Lepidoptera,

MACH2

Coleoptera

\subsubsection{Synthesis and structure-activity relationships (SAR).}

The synthesis of symmetrical and asymmetrical 1,2-dibenzoyl-1-t-butyl hydrazines can be achieved by the following two step reaction shown in Fig. 2. In 1984, during the process of synthesizing compound number 1 in Fig. 2, which was to be used for the synthesis of another class of compounds, Hsu (Rohm and Haas Company) obtained an additional undesired product (Fig. 2), 1,2-di(4chlorobenzoyl)-1-tbutylhydrazine (A 1/4 4-Cl). Testing of this undesired by-product revealed that it had ecdysteroid activity, and eventually led to the development of a bisacylhydrazine class of compounds. This serendipitous discovery can be attributed to the inquiring mind of Hsu, who decided to test this compound for biological activity even though it was a contaminant! By treating equivalent amounts of different benzoyl chlorides with 1 (benzoyl hydrazide), unsubstituted analogs (3) can be prepared as shown in Fig. 2. 
<smiles>CC(C)(C)NNC(=O)c1ccccc1</smiles>

2

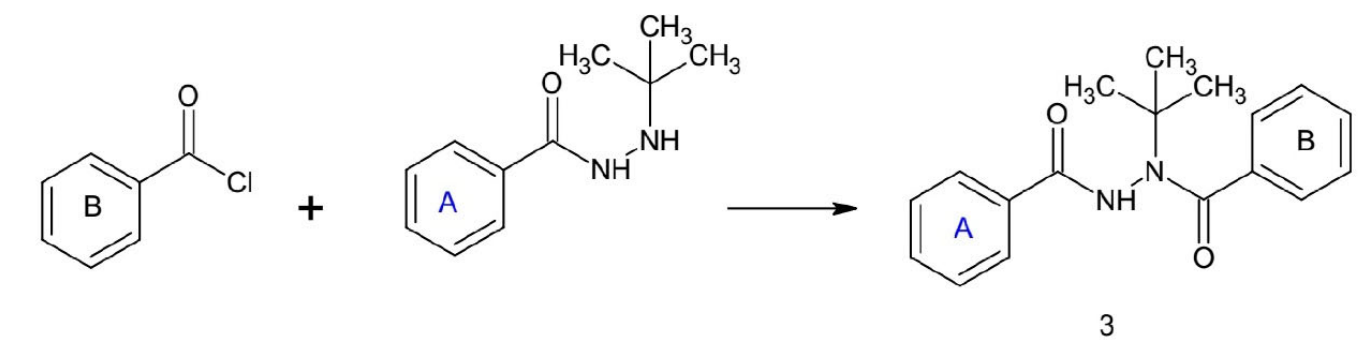

Fig. 2. Synthetic routes for unsubstituted and substituted bisacylhydrazines.

Between 1985 and 1999, approximately 4000 structural bisacylhydrazine analogs were synthesized at the Rohm and Haas Company. This resulted in the selection of 22 candidate compounds for field testing; three of these were selected for commercial development. Extensive SAR research was carried out around the bisacylhydrazine chemistry to discover additional more potent nonsteroidal agonists with different pest spectrum activity. ${ }^{47}$

\section{Types of insect growth regulators}

IGRs are usually classified according to their mode of action. Sometimes, however, terminology related to their chemical structure is also practiced; for example, most chitin synthesis inhibitors are benzoylphenylurea derivatives and the term 'benzoylphenylurea' is often used in the literature. There are three types of IGRs, each of which has a different mode of action. ${ }^{48}$

\subsection{Chitin synthesis inhibitors.}

Chitin, the (14) glycoside polymer of $N$-acetyl-D-glucosamine, is a major structural component of insect cuticles. ${ }^{49}$ In addition to the insect cuticles, chitin is also present in cell walls of fungi and protozoa, but is absent in higher plants and vertebrates. ${ }^{41}$ Chitin synthesis inhibitors (CSIs), which can interfere with chitin formation, will affect the normal growth and development process of insects and fungi but have no effect on plants and vertebrates. ${ }^{50}$ The unique mode of action coupled with excellent activity on target and lower toxicity to non-target organisms (including many beneficial arthropods) made these compounds a new tool for integrated pest management. ${ }^{51}$ Benzoylphenylureas have been developed as a typical kind of chitin synthesis inhibitors since dimilin (diflubenzuron) was introduced into market in the 1970s. The first chitin synthesis inhibitor introduced into the market as a novel insecticide was benzoylphenylurea, diflubenzuron. It was considered a potent compound against larvae of common cutworm, Spodoptera littoralis (Fabr.) and Cydiapomonella L. Some of the structural modifications (derivatives) of the compound are more active than the parent compound, these prevent the formation of chitin, a carbohydrate that is an important structural component of the insect's 
exoskeleton. ${ }^{52}$ When treated with one of these compounds, the insect grows normally until the time to molt. ${ }^{53}$ When the insect molts, the exoskeleton is not properly formed and it dies. Death may be quick, but in some insects it may take several days. As well as disrupting molting, chitin synthesis inhibitors can kill eggs by disrupting the normal development of the embryo Chitin, ${ }^{54}$ a polysaccharide, is a very stable major component of the insect cuticle. It is a long-chain polymer of the amino-sugar, $\mathrm{N}$-acetyld-glucosamine. ${ }^{55}$ CSIs inhibit the action of chitin synthase, resulting in abnormal, malformed, new cuticle. Consequently, the insect dies in the molt, or the abnormal cuticle causes mortality after the molt. $^{56}$

\subsection{Juvenile Hormone Analogs (JHAs) and mimics.}

A study extirpated the brain of a caterpillar and demonstrated that this prevented pupation; he attributed this phenomenon to a humoral factor produced by the brain. ${ }^{57}$ This discovery heralded the study of hormonal regulation of metamorphosis in insects. Later, Wigglesworth described the secretion of a hormone that prevents metamorphosis from a pair of glands, the corpora allata (CA) attached to the base of the brain; he called it the "status quo" or juvenile hormone (JH) ${ }^{58}$ A few years later, Fukuda described the prothoracic glands as the source of the molting hormone or ecdysone, ${ }^{59}$ which was later characterized as a steroidal hormone. ${ }^{60}$ At this time, Williams made the now famous statement "third generation pesticides" in describing the use of JHs as environmentally safe control agents to which the insect will be unable to develop resistance, ${ }^{61}$ the first and second generation pesticides being the inorganic and the chlorinated hydrocarbons, respectively.

\section{Advantages and disadvantages of IGRs}

IGRs are usually nontoxic or slightly toxic to vertebrates. Therefore, their impact on the environment is minimal, though they may affect beneficial insects (bees, pollinators, insect predators, and parasites of pest) and also crustaceans and other arthropods. The selectivity of IGRs to a certain group of insects is an environmental advantage, but disadvantage for marketing. ${ }^{62}$ A major disadvantage is that IGRs are effective only at special stages or instars (CSIs and ecdysteroid agonists before molt, JHAs at the last larval instar) and do not prevent some or all damage by the larvae. The belated mortality is an important psychological disadvantage the farmer does not see dead insects immediately and consequently doubts the efficiency of the IGR. Outdoor stability of IGRs is usually satisfactory; if too short, encapsulation, allowing slow release, is practiced. Environmental degradation is also satisfactory. In contrast to some earlier beliefs, insects are able to develop resistance to IGRs. Development of new IGRs and their approval by the authorities are costly, especially in relation to marketing limitations. Nevertheless, new IGRs appear on the market and more effective IGRs, based on " anti-JH' or " antiecdysteroid"' action may be developed in the future.

\section{Epoxidation Methods and Processes}

Poly-functional epoxy compounds are very reactive building blocks and can lead to materials by chain-growth polymerization or cross linking with anhydrides, phenols and amines. They are generally prepared by direct glycidylation, as shown in (Scheme 1) ${ }^{63,64}$ It consists in reacting an alcohol or amine derivative with epichlorohydrin $(\mathrm{ECH})$ in the presence of an alkylammonium halide as a phase transfer catalyst, such as benzyltriethylammonium chloride, tetrabutylammonium bromide or cetyltrimethyl

ammonium chloride. Sometimes, epibromohydrin is used instead of its chloride analogue. ${ }^{65}$ A sodium or potassium hydroxide post-treatment is usually applied in same pot to increase the number of epoxy rings. In fact, the phenolic oxygen may displace the chlorine atom to directly yield the desired product via a $\mathrm{S}_{\mathrm{N}} 2$ mechanism, or open the epoxy ring causing the formation of a chlorinated derivative that can be closed by a strong base through a $S_{N} 1$ mechanism (Scheme 2). ${ }^{66,67} S_{N} 1$ stands for internal Nucleophilic Substitution and is a nucleophilic substitution mechanism that implies a retention of configuration. 


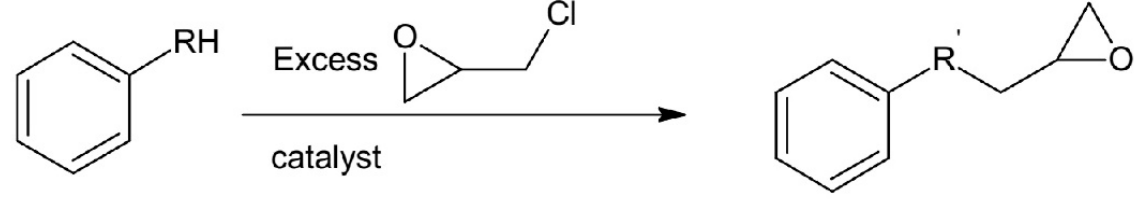

$$
\begin{gathered}
\mathrm{R}=\mathrm{O}, \mathrm{R}^{\prime}=\mathrm{O} \\
\mathrm{R}=\mathrm{NH}, \mathrm{R}^{\prime}=\mathrm{N}-\mathrm{CH}_{2} \text {-epoxy }
\end{gathered}
$$

Scheme 1. Synthesis of epoxy derivatives from phenol or aniline by direct glycidylation with epichlorohydrin.

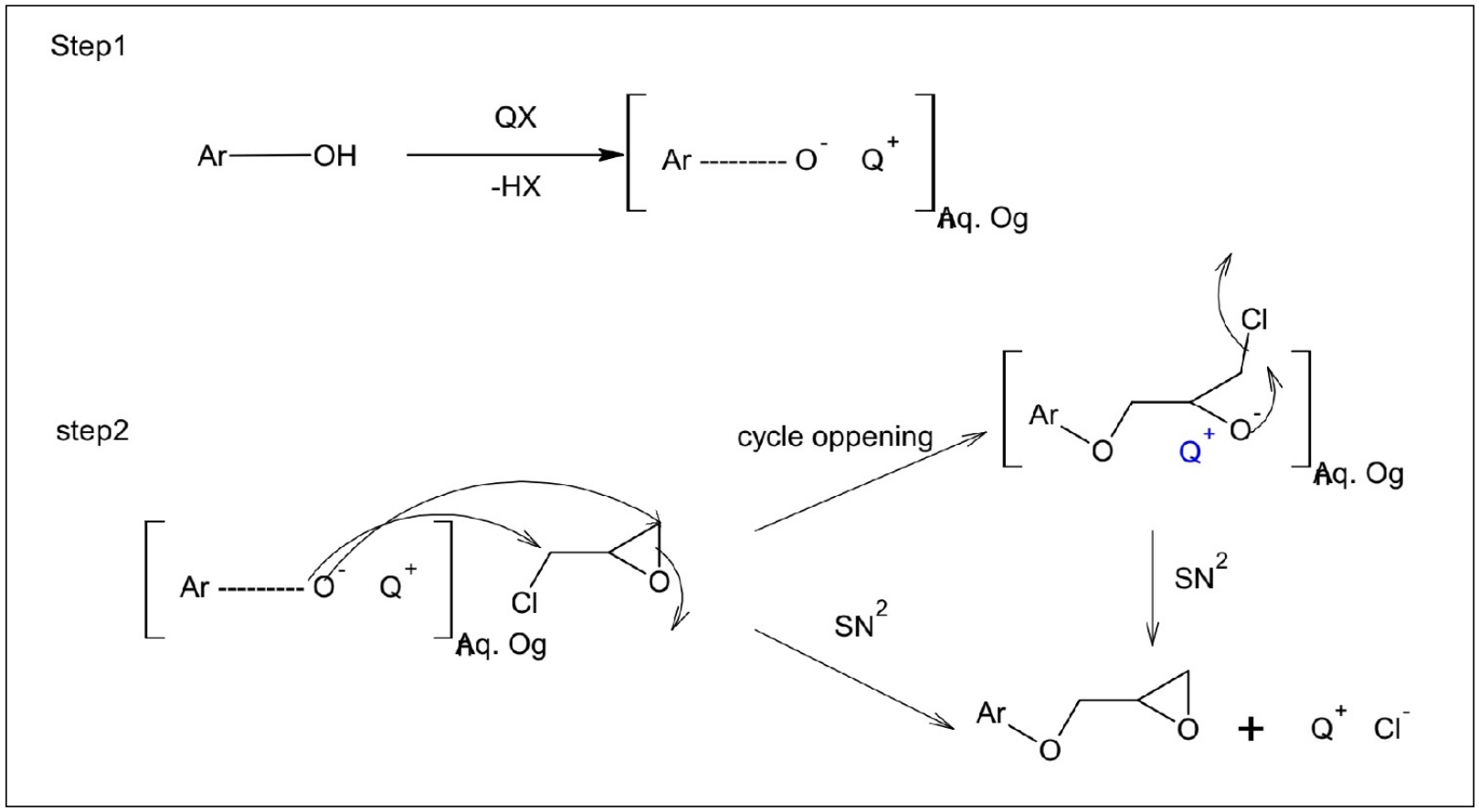

Scheme 2. Mechanism of coupling between phenolic compounds and epichlorohydrin $(\mathrm{ECH})$ in the presence of a phase transfer catalyst (QX).

The direct glycidylation of phenol has proven to yield several possible side products including chlorinated and diol derivatives (Fig. 3) ${ }^{6}{ }^{6}$ Furthermore, the higher reactivity of benzoic acid may lead to an opening of the epoxy via both carbon atoms, leading to new chlorinated (B2), diol (B3) and oxetane ring (B1) side-products. ${ }^{69,70}$ Another important side-product observed during the glycidylation step with epichlorohydrin is a benzodioxan derivative obtained by an intra cyclization occurring with two phenolic groups in ortho position (Scheme 3).

To avoid these drawbacks, ${ }^{71}$ a process was developed to obtain glycidyl derivatives from phenol, glycidol and propylene carbonate but it requires the use of high temperatures in autoclave and relatively harsh conditions. A two-steps synthesis can also be used to form epoxy compounds: it involves the $O$ or $N$-allylation of the corresponding alcohol or amine derivatives using an allyl halide, followed by the oxidation of the resulting double bond (Scheme 4). Unfortunately, allyl chloride and allyl bromide are both toxic derivatives. Moreover, hydrogen peroxide exhibitis low reactivity toward allyl ether oxidation except at high concentrations or in the presence of metal transition catalysts. ${ }^{72}$ The use of stronger, more toxic peracids such as $(m \mathrm{CPBA})$ is sometimes considered, but it was found that found that an excess of peracid is also required and the $m$-chlorobenzoic acid formed during the oxidation of allylated gallic acid is difficult to eliminate. ${ }^{63}$ The epoxidation of allyl groups by potassium 
peroxymonosulfate (also known as Oxone) can be considered a sustainable pathway. It is based on the Shi epoxidation, which uses a fructose-derived organocatalyst with Oxone and ketones to generate in situ dioxiranes, ${ }^{73}$ which are strong epoxidating agents. However, the epoxidation of electron-deficient alkenes such as allyl groups by dioxiranes can be very slow. ${ }^{74}$ The reaction may require the use of ketones bearing highly electron attractive groups such as 1,1,1-trifluoroacetone to increase the overall yield. ${ }^{75}$ Enzymatic catalysts have also been developed as greener alternatives for the oxidation of carbon-carbon double-bonds. First developed to replace the Prileshajev reaction applied at an industrial scale to produce epoxy vegetable oils, ${ }^{76}$ one of these catalysts (immobilized lipase B from Candida antarctica (Novozym 435)) has also been used to obtain epoxy gallic acid and vanillic acid from their allylated precursors in high yields. ${ }^{72}$<smiles>c1ccc(OCC2CO2)cc1</smiles>

(A1)<smiles>O=C(OC1COC1)c1ccccc1</smiles>

(B1)<smiles>OC(CCl)COc1ccccc1</smiles>

(A2)<smiles>O=C(OC(CO)CCl)c1ccccc1</smiles>

(B2)<smiles>OCC(O)COc1ccccc1</smiles>

(A3)<smiles>O=C(OC(CO)CO)c1ccccc1</smiles>

(B3)

Fig. 3. Common side-products of the direct glycidylation of phenol (A1-A3) and benzoic acid (B1B3).

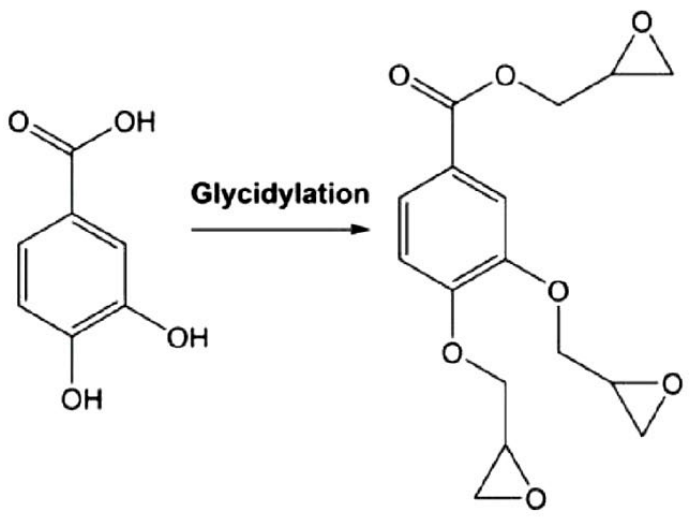

$60 \%$

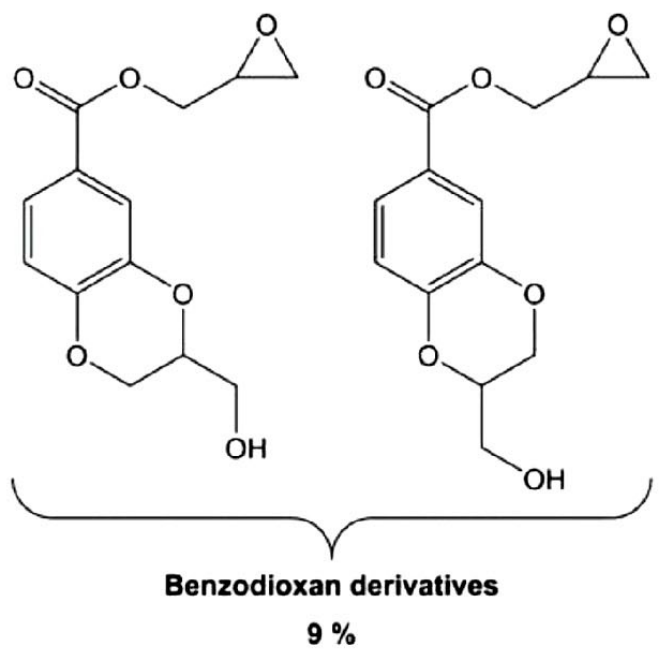

$9 \%$

Scheme 3. Products obtained during the glycidylation of protocatechuic acid with epichlorohydrin. 
<smiles>[R]c1ccccc1</smiles><smiles>[X]CC=C</smiles><smiles>[R]c1ccccc1</smiles>

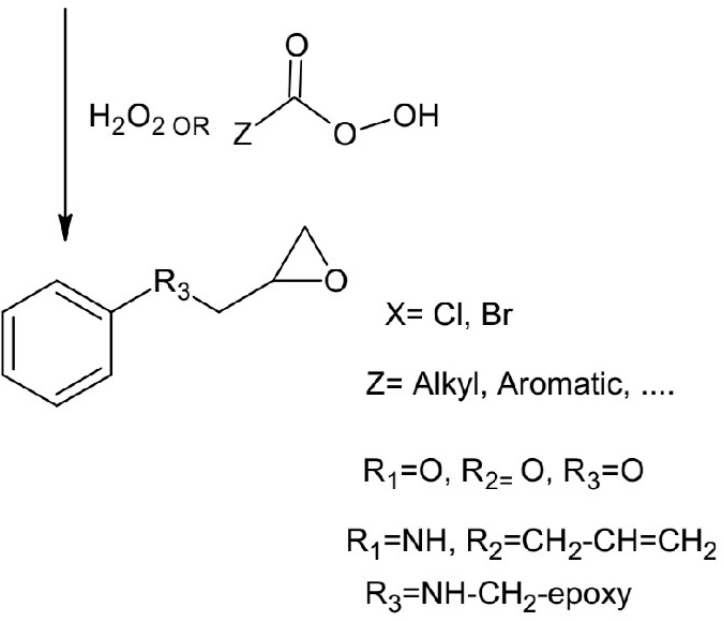

Scheme 4. Synthetic pathway to obtain epoxy from phenol or aniline using allyl halide and oxidation.

Overall, the direct glycidylation remains the main synthetic pathway used for the industrial synthesis of Diglycidyl Ether of Bisphenol A, as it allows the recovery of both monomers and oligomers for tunable properties. ${ }^{77-79}$ By reacting bisphenol A with a controlled excess of epichlorohydrin, the "taffy" process yields either monomers or short oligomers of DGEBA (Scheme 5). To increase the chain length of the oligomers, "advancement" (with solvent) or "fusion" (without solvent) processes can be chosen. They both consist in reacting BPA with an excess of a pre-synthesized DGEBA monomer to extend the chain. "Fusion" process is generally preferred for the industrial production of DGEBA oligomers as the purification steps are easier and the chlorine content of the final product is lower than in the case of the "taffy" process, which requires an excess of epichlorohydrin.

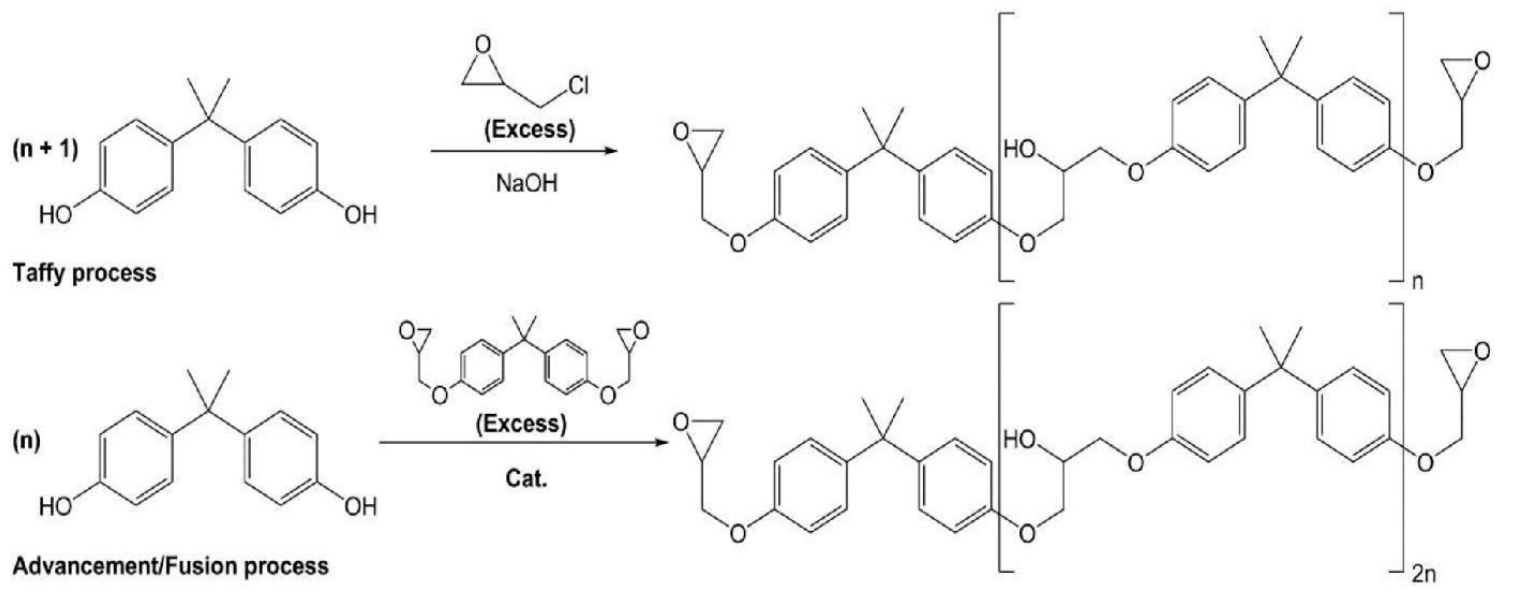

Scheme 5. Two main industrial processes for the synthesis of monomers and oligomers of diglycidyl ether of vanillyl alcohol (DGEBA): (i) the taffy process with a controlled excess of epichlorohydrin and (ii) the advancement/fusion process using an excess of a pre-synthesized DGEBA monomer. 


\section{Main Natural Sources of Aromatic Moieties}

The present part will briefly summarize the main sources of aromatic moieties bearing reactive groups suitable for the introduction of epoxy moieties. This summary will include resources naturally containing small, phenolic compound such as eugenol extractible from plant natural oils, or polyphenolic crosslinked polymers such as tannins and lignin that can be directly functionalized or depolymerized into smaller molecules prior to epoxidation steps. Some information on their availability or worldwide production will be given as well as the main known characteristics of their structure.

\subsection{Lignin}

Lignin is the widest distributed aromatic biopolymer and the second most abundant naturally occurring macromolecule after cellulose, constituting from $1 \%$ to $43 \%$ by weight of the dry lignocellulosic biomass, with a potential availability exceeding 300 billion tons. ${ }^{80}$ It is a cell-wall component bonding cells together in the woody stems, providing them with their well-known rigidity and impact resistance. Although its absolute structure remains unknown and varies according to the plant it originates from and its environment, lignin is an amorphous three-dimensional polymer network of three main methoxylated phenyl propane units (Fig. 4) with seven major linkages: $\beta-O-4$ (aryl ether), $\alpha-O-4, \beta-\beta$ (pinoresinol), $\beta-5$ (phenylcoumaran), $\beta-1$ (diphenylmethane), 5,5 and 4- $O-5$ (diphenyl ether) linkages. It exhibits various functional groups such as aliphatic and phenolic hydroxyl, carboxylic, carbonyl and methoxy moieties.

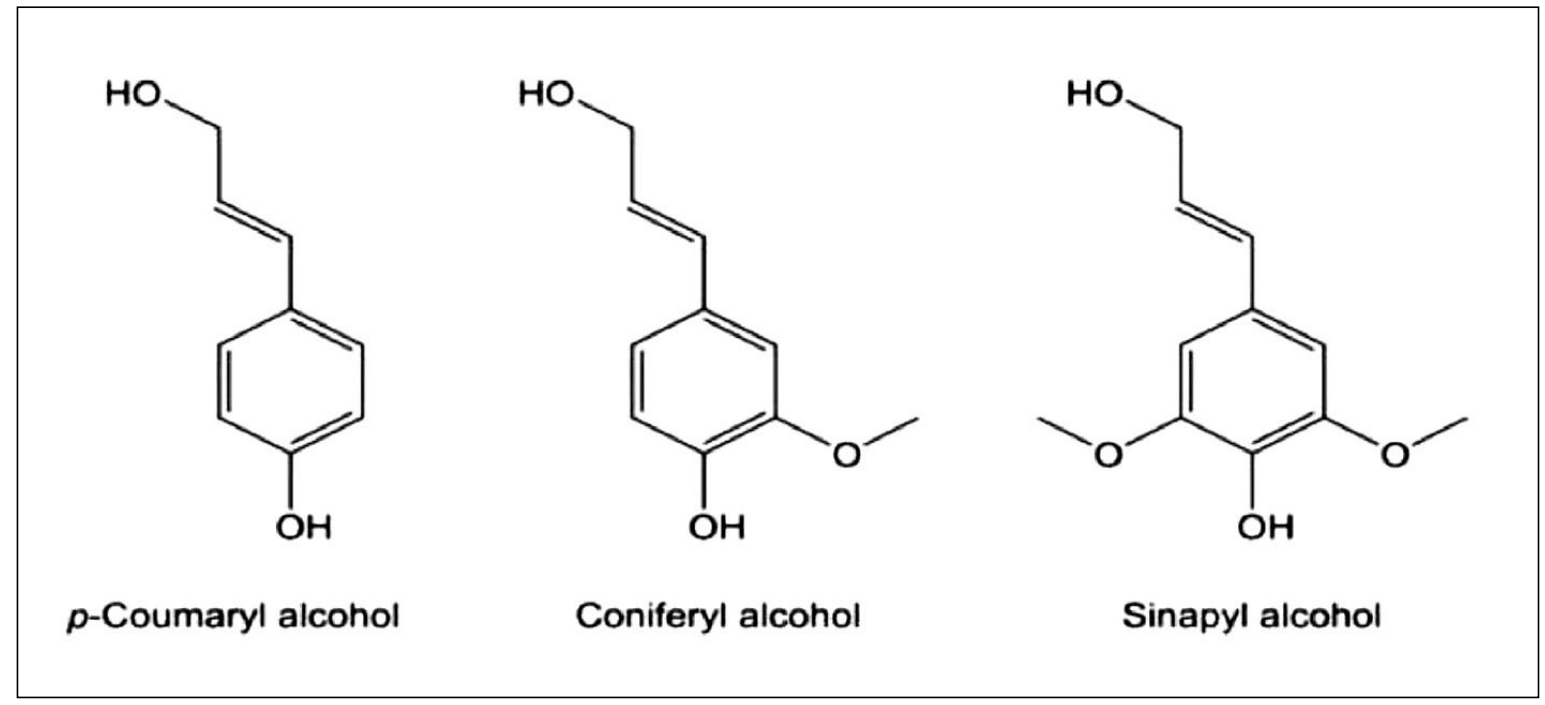

Fig. 4. Main aromatic subunits found in lignin.

Usually, lignin is viewed as a waste material derived from the wood pulp in the paper industry and available in large quantity (50-70 million of tons estimated). ${ }^{81}$ Unfortunately, only $1 \%$ to $2 \%$ of overall lignin is used for more specific applications, the remaining primarily serving as a (bio)fuel for the cellulose extraction. ${ }^{82}$ Lignin is extracted from lignocellulosic biomass by two main categories of processes: (i) sulfur processes yielding lignosulfate and Kraft lignin and (ii) sulfur-free processes yielding organosolv and soda lignin. These extraction methods greatly influence the already complex structure of the polymer, sometimes making it difficult to directly use it as a chemical precursor. For this reason, works have been carried out to depolymerize lignin into smaller, simpler aromatic molecules suitable for chemical modification and/or polymerization. For example, when lignin is depolymerized, compounds such as vanillin, phenols derivatives, cresols, ferulic and coumaric acids are released (Fig. 5). All these molecules are already oil-based but this pathway offers an interesting solution for their renewability, thus increasing thermosets renewability. 
<smiles>c1ccccc1</smiles><smiles>Cc1ccccc1</smiles><smiles>Cc1ccccc1C</smiles><smiles>Oc1ccccc1</smiles><smiles>COc1ccccc1</smiles><smiles>Cc1ccccc1O</smiles><smiles>COc1ccccc1O</smiles><smiles>COc1cccc(OC)c1O</smiles><smiles>[R]CCCC1CCC(O)C(OC)C1</smiles><smiles>[R]CCCc1ccc(O)c(OC)c1</smiles><smiles>[R]C(=O)c1cc([R2])c(O)c([R])c1</smiles>

\begin{tabular}{c|c|c|}
$\mathbf{R}_{\mathbf{1}}$ & $\mathbf{R}_{\mathbf{2}}$ & $\mathbf{R}_{\mathbf{3}}$ \\
$\mathbf{H}$ & $\mathrm{H}$ & $\mathrm{H}$ \\
$\mathrm{H}$ & $\mathrm{OMe}$ & $\mathrm{H}$ \\
$\mathrm{H}$ & $\mathrm{OMe}$ & $\mathrm{OMe}$ \\
$\mathrm{OH}$ & $\mathrm{H}$ & $\mathrm{H}$ \\
$\mathrm{OH}$ & $\mathrm{OMe}$ & $\mathrm{H}$ \\
$\mathrm{OH}$ & $\mathrm{OMe}$ & $\mathrm{OMe}$ \\
$\mathrm{OH}$ & $\mathrm{OMe}$ & $\mathrm{CHO}$ \\
$\mathrm{OH}$ & $\mathrm{OMe}$ & $\mathrm{H}$ \\
$\mathrm{OH}$ & $\mathrm{OMe}$ & $\mathrm{COOH}$
\end{tabular}

Fig. 5. Various aromatic moieties obtained from lignin depolymerization.

\subsection{Tannins}

Tannins are the second bio-based source of natural phenolic moieties and the third most abundant compounds extracted from wood biomass, with 160,000 tons bio-synthesized each year. ${ }^{83}$ They can be found mainly in the soft tissues such as wood, bark, leaves or needles of all vascular and some nonvascular plants, in which they play a protective role against outside aggressions and in plant growth regulation. ${ }^{84}$ Tannins are polyphenol derivatives with low molecular weights and can be divided into three main categories: hydrolysable tannins, condensed tannins and complex tannins, the latter being a combination of the first two (Fig. 6).

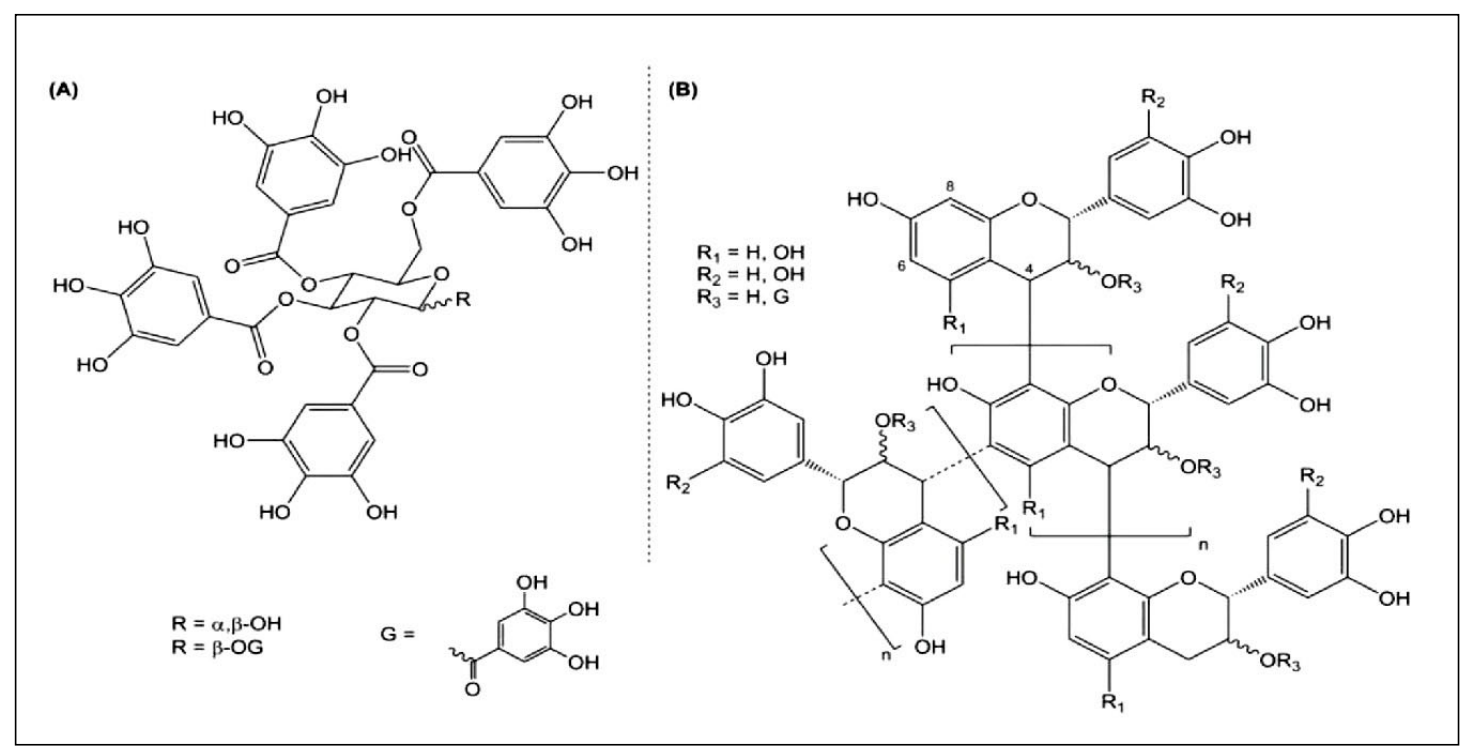

Fig. 6: Main structures of tannins from vascular plants: hydrolysable tannins (A) and condensed tannins (B). 
A last class of tannins, phlorotannins, can be found in non-vascular plants such as algae and are based on polymerized phloroglucinol (1,3,5-trihydroxybenzene) with a large range of molecular weights. They play a role similar to condensed tannins in vascular plant and can as well be divided into categories according to the link between phloroglucinol units e.g., ether, phenyl bonds, a combination of both, or a dibenzo- $p$-dioxin bond (Fig. 7).

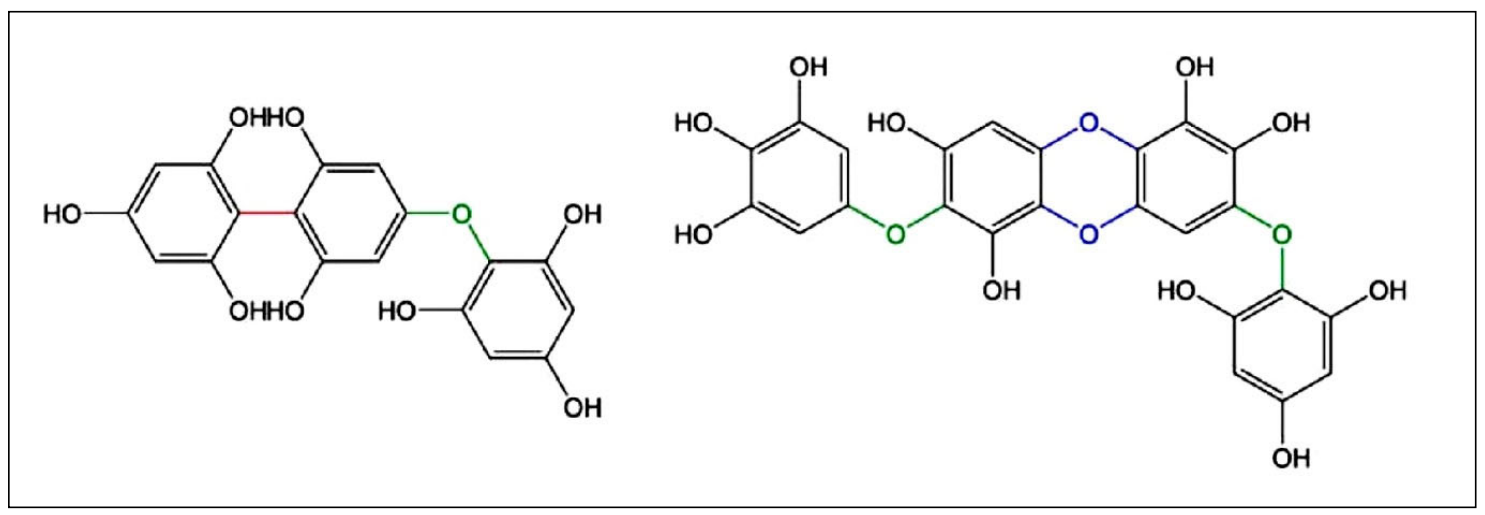

Fig. 7. Example of phlorotannins linkages with phenyl bonds (in red), ether bonds (in green) and dibenzo-p-dioxin bond (in blue).

\subsection{Cardanol}

(CNSL) is a reddish-brown liquid that can be extracted from the soft honeycomb structure located inside the cashew nut shell and constitutes from 30 to $35 \mathrm{wt} \%$ of it. ${ }^{85}$ With approximately 2.1 millions of tons of cashew nuts produced every year, mainly from countries in Asia (India, Vietnam) and Africa (Nigeria, Ivory Coast), CNSL represents an abundant non-edible by-product that has already found various applications in coatings, laminates and adhesives to name a few.

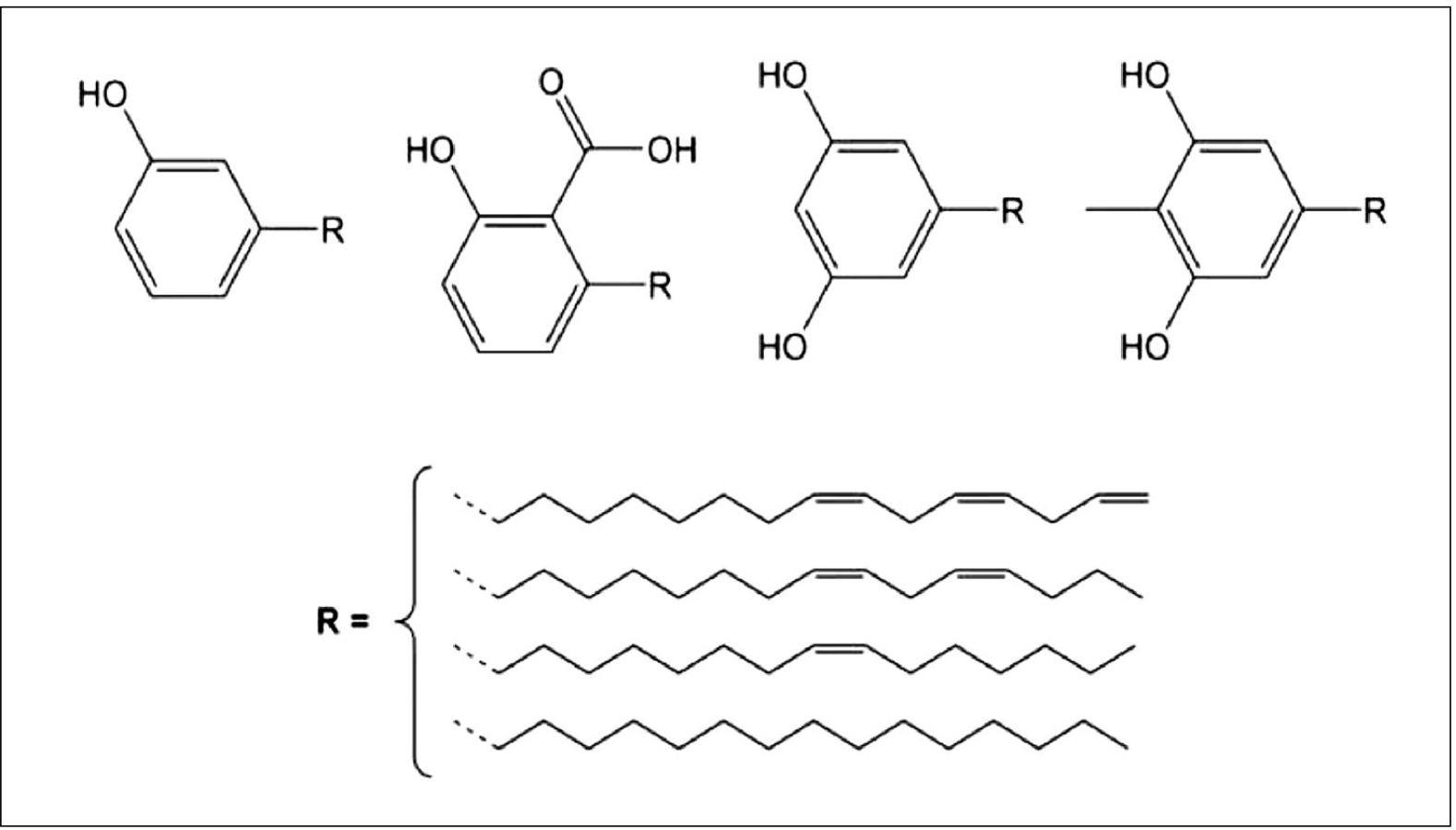

Figure 8: Main phenolic constituents of cashew nut shell liquid (from left to right): cardanol, anacardic acid, cardol and 2-methyl cardol. 
However, it also represents an interesting source of aromatic chemical building blocks. In fact, CNSL is mainly composed of four major phenolic derivatives: anacardic acid, cardanol, cardol and 2methyl cardol (Fig. 8), the percentage of which depends on the extraction method. Among these, cardanol is often regarded as the most interesting compound, as its percentage can reach $60 \%$ in some CNSL grades. Its structure is defined as a mono-aromatic phenol substituted in meta-position by a C15 alkyl chain, on which none to three unsaturations in $\mathrm{C} 8, \mathrm{C} 11$ and $\mathrm{C} 14$ are possible. Thanks to its hydroxyl function and carbon-carbon double bond(s), cardanol can offer various functionalization opportunities, although its long aliphatic chain may severely impact materials in terms of thermomechanical properties.

\subsection{Cellulose and Hemi-Cellulose}

Cellulose is the most abundant naturally occurring polymer and accounts for approximately $40-45$ wt \% of lignocellulosic biomass depending of wood species. ${ }^{86}$ With an annual production estimated around 100 billion tons, it is a remarkable feedstock for the synthesis of renewable chemical building blocks. Cellulose is a crystalline high molecular weight polysaccharide (7000 to 15,000 monomeric units) formed of D-glucose linked by $\beta$-1,4-glycosidic bonds. The high chain organization through hydrogen bonding provides cellulose with interesting mechanical properties as well as poor solubility in water and various organic solvents. However, the several hydroxyl groups along its backbone make cellulose highly hydrophilic. Although it does not exhibit an aromatic structure, aromatic building blocks can be obtained from cellulose via depolymerization. ${ }^{87}$ Through acid hydrolysis under harsh conditions or bacterial degradation, cellulose yields glucose that can further isomerize into fructose and then be dehydrated into 5- hydroxymethyl-2-furfural (HMF), a furanic aldehyde. ${ }^{88} \mathrm{HMF}$ can also be oxidized into 2,5-furandicarboxylic acid or reduced into 2,5-furandimethanol, two symmetric difunctional aromatic moieties.

The other main component of lignocellulosic biomass, namely hemi-cellulose, is an amorphous polysaccharide with short chains of 500 to 3000 monomer units with acidic groups. Similarly to cellulose, it can be depolymerized into pentose that can further be transformed into 2- furfural, 2furanmethanol and 2-furancarboxylic acid. However, these derivatives are mono-functional, thus making them unsuitable for the synthesis of di-epoxy monomers, only fit for reactive diluents. It is also worth noting that cellulose can also be degraded into other interesting, although non aromatic, building blocks: levulinic and lactic acids.

\subsection{Other Natural Sources of Aromatic Moieties}

Some other abundant biomasses are potential candidate to extract or synthesize phenolic derivatives. For example, terpenes and terpenoids can be obtained from various plants' essential oils or as byproducts of industrial processes and are largely available at reasonable prices. ${ }^{89}$ For example, 700 millions of $\mathrm{kg}$ of limonene are produced annually as a side-product of orange juice production. Terpenes form a large and diverse class of molecules based on repeating isoprene units that can be linked head to tail or form cycloaliphatic or aromatic rings such as in $\alpha$-pinene found in pines, limonene from citrus fruits or $p$-cymene extracted from thyme, only to name a few. Some of them may represent interesting candidates for the synthesis of epoxy monomers such as carvacrol, which exhibits a phenol moiety and a carbon-carbon double bond (Scheme 6) and can be isolated from oregano and thyme essential oils. However, not all terpenoids contain aromatic and/or phenolic moieties, but these requirements can be reached via different synthesis steps. For example, carvacrol can be obtained from other turpentine components such as limonene via an oxidation followed by an isomerization with sulfated zirconia or from $p$-cymene by the action of concentrated sulfuric acid and sodium hydroxide. ${ }^{90}$ 


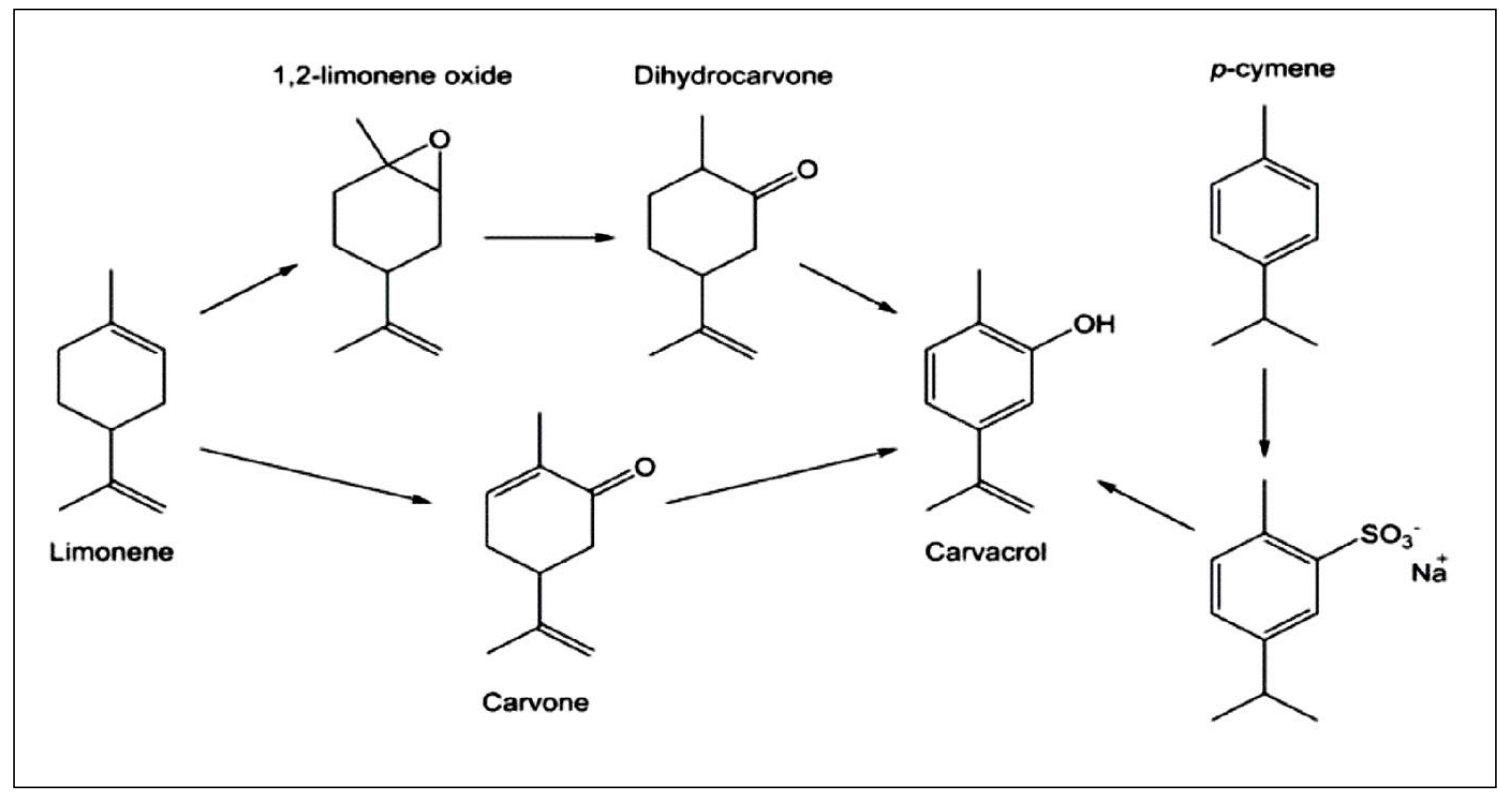

Scheme 6. Synthesis of carvacrol from limonene or $p$-cymene.

Other phenolic compounds can be extracted from various plant essential oils such as 4-allyl-2methoxyphenol, commonly known as eugenol (Fig. 9), obtained from clove oil where it accounts for $80 \%$ Jamaican chili, cinnamon and bay leaves from California. ${ }^{91}$ It is a renewable resource, but it is also considered safe, non-carcinogenic and non-mutagenic by the U.S. Food and Drug Administration and used as a food flavoring agent. Furthermore, it exhibits several pharmacological properties such as anesthetic, antioxidant, and antimicrobial activities. Apart from extraction, eugenol can be synthesized by allylation of guaiacol, another bio-based phenolic derivative. The main advantage of eugenol is that it exhibits a carbon-carbon double bond with fair reactivity and a phenolic group, thus allowing various functionalizations.

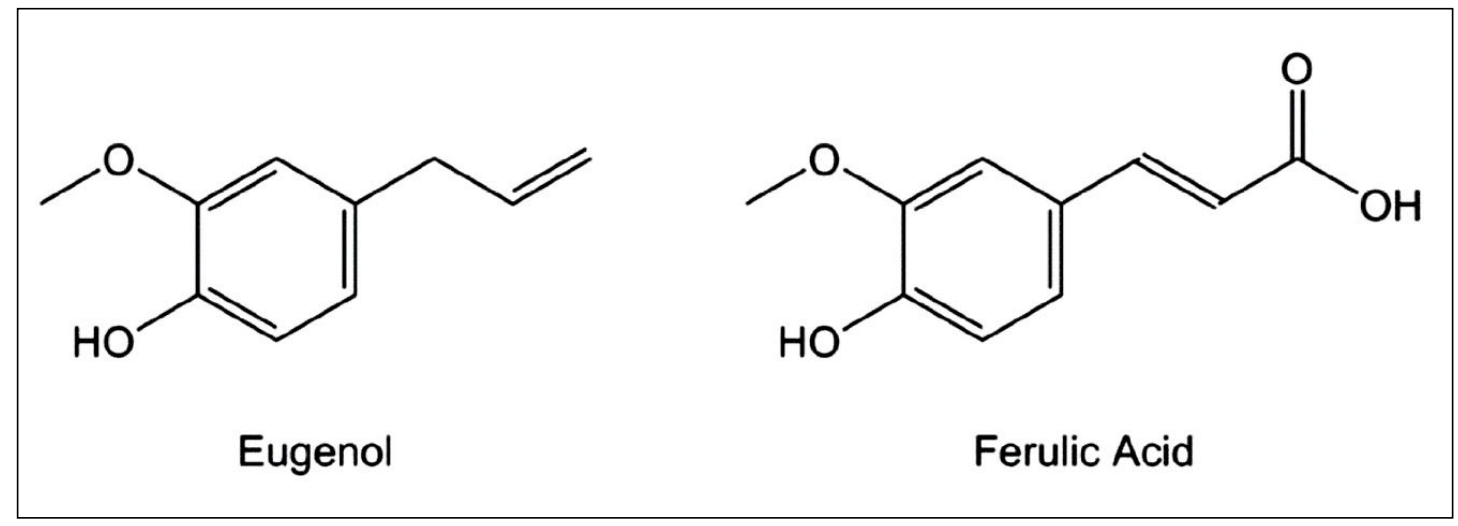

Fig. 9. Structures of eugenol and ferulic acid.

Lignocellulosic biomass may also contain $p$-coumaryl, coniferyl and sinapyl acids, depending on the plant species, that act as crosslinkers between lignin and polysaccharides (cellulose and hemicellulose) to increase the rigidity of the materials. Among these, 3- methoxy-4-hydroxycinnamic acid (Fig. 9), also known as ferulic acid, is an abundant derivative that can be extracted in good yields from various non-food resources such as bagasse, rice, wheat and sugar beet roots and has both a hydroxyl group and an aliphatic carboxylic acid, ${ }^{92}$ thus enabling functionalization. It also exhibits antioxidative, anti-tumor, photoprotective and anti-hypertensive activities. 


\section{References}

(1) Bakhite E. A., Abd-Ella A. A., El-Sayed M. E. A., and Abdel-Raheem Sh. A. A. (2014) Pyridine derivatives as insecticides. Part 1: Synthesis and toxicity of some pyridine derivatives against Cowpea Aphid, Aphis craccivora Koch (Homoptera: Aphididae). J. Agric. Food Chem., 62 (41) 9982-9986.

(2) Nirwan N., Pareek Ch., and Swami V. K. (2020) Indolylimidazoles: Synthetic approaches and biological activities. Curr. Chem. Lett., 9 (2020) 31-50.

(3) Bakhite E. A., Abd-Ella A. A., El-Sayed M. E. A., and Abdel-Raheem Sh. A. A. (2017) Pyridine derivatives as insecticides. Part 2: Synthesis of some piperidinium and morpholinium cyanopyridinethiolates and their Insecticidal Activity. J. Saud. Chem. Soc., 21 (1) 95-104.

(4) Kamal El-Dean A. M., Abd-Ella A. A., Hassanien R., El-Sayed M. E. A., Zaki R. M., and AbdelRaheem Sh. A. A. (2019) Chemical design and toxicity evaluation of new pyrimidothienotetrahydroisoquinolines as potential insecticidal agents. Toxicol. Rep., 6 (2019) 100104.

(5) Saddik A. A., Kamal El-Dean A. M., El-Said W. A., Hassan K. M., and Abbady M. S. (2018) Synthesis, Antimicrobial, and Anticancer Activities of a New Series of Thieno[2,3- $d$ ] Pyrimidine Derivatives. J. Heterocyclic Chem., 55 (9) 2111-2122.

(6) Saddik A. A., Kamal El-Dean A. M., El-Sokary G. H., Hassan K. M., Abbady M. S., Ismail I. A., and Saber S. H. (2017) Synthesis and Cytotoxicity of Some Thieno[2,3-d]pyrimidine Derivatives. $J$. Chin. Chem. Soc., 64 (1) 87-93.

(7) Kamal El-Dean A. M., Abd-Ella A. A., Hassanien R., El-Sayed M. E. A., and Abdel-Raheem Sh. A. A. (2019) Design, Synthesis, Characterization, and Insecticidal Bioefficacy Screening of Some New Pyridine Derivatives. ACS Omega, 4 (5) 8406-8412.

(8) Abdel-Raheem Sh. A. A., Kamal El-Dean A. M., Zaki R. M., Hassanien R., El-Sayed M. E. A., Sayed M., and Abd-Ella A. A. (2021) Synthesis and toxicological studies on distyryl-substituted heterocyclic insecticides. Eur. Chem. Bull., 10 (4) 225-229.

(9) Tolba M. S., Sayed M., Abdel-Raheem Sh. A. A., Gaber T. A., Kamal El-Dean A. M., and Ahmed M. (2021) Synthesis and spectral characterization of some new thiazolopyrimidine derivatives. Curr. Chem. Lett., Accepted Manuscript (DOI: 10.5267/j.ccl.2021.4.004).

(10) Abdel-Raheem Sh. A. A., Kamal El-Dean A. M., Hassanien R., El-Sayed M. E. A., and Abd-Ella A. A. (2021) Synthesis and characterization of some distyryl-derivatives for agricultural uses. Eur. Chem. Bull., 10 (1) 35-38.

(11) Abdel-Raheem Sh. A. A., Kamal El-Dean A. M., Hassanien R., El-Sayed M. E. A., and Abd-Ella A. A. (2020) Synthesis and biological activity of 2-((3-Cyano-4,6-distyrylpyridin-2yl)thio)acetamide and its cyclized form. Alger. j. biosciences, 01 (02) 046-050.

(12) Lingappa M., Guruswamy V., and Bantal V. (2021) Synthesis and characterization of 4-amino4H-1,2,4-triazole derivatives: Anticonvulsant activity. Curr. Chem. Lett., 9 (2021) 33-42.

(13) Al-Taifi E. A., Abdel-Raheem Sh. A. A., and Bakhite E. A. (2016) Some reactions of 3-cyano-4(p-methoxyphenyl)-5-oxo-5,6,7,8-tetrahydroquinoline-2(1H)-thione; Synthesis of new tetrahydroquinolines and tetrahydrothieno[2,3-b]quinolines. Assiut University Journal of Chemistry (AUJC), 45 (1) 24-32.

(14) Abdel-Raheem Sh. A. A., Kamal El-Dean A. M., Hassanien R., El-Sayed M. E. A., Sayed M., and Abd-Ella A. A. (2021) Synthesis and spectral characterization of selective pyridine compounds as bioactive agents. Curr. Chem. Lett., 10 (2021) 255-260.

(15) Chavan P., Pansare D., Shelke R., Shejul S., and Bhoir P. (2021) Ultrasound-assisted synthesis and biological significance of substituted $4 \mathrm{H}$-chromene-3- carbonitrile using greenery approaches. Curr. Chem. Lett., 10 (2021) 43-52.

(16) Su N. Y., and Scheffrahn R. H. (1990) Potential of insect growth regulators as termiticides: a review. Sociobiology, 17 (2) 313-328. 
(17) Steelman C. D., Farlow J. E., Breaud T. P., and schilling P. E. (1975) Effects of insect growth regulators on psorophora columbiae (Dyar and Knab) and non-target aquatic insect species in rice fields. Mosq. News, 35 (1) 67-76.

(18) Ganyard M. C., Bradley Jr J. R., Boyd F. J., and Brazzel J. R. (1977) Field evaluation of diflubenzuron (Dimilin) for control of boll weevil reproduction. J. Econ. Entomol., 70 (3) 347-350.

(19) Bowers W. S., Ohta J. S., and Marsella P. A. (1979) Discovery of insect antijuvenile hormones in plants. Science, 193 (4253) 542-547.

(20) Brooks G. T. (1986) Insecticide metabolism and selective toxicity. Xenobiotica, 16 (10-11) 9891002.

(21) Medina P., Smagghe G., Budia F., Tirry L., and Vinuela E. (2003) Toxicity and absorption of azadirachtin, diflubenzuron, pyriproxyfen, and tebufenozide after topical application in predatory larvae of Chrysoperla carnea (Neuroptera: Chrysopidae). Environ. Entomol., 32 (1) 196-203.

(22) Mitsui T., Nobusawa C., and Fukami G. (1984) Mode of inhibition of chitin synthesis by diflubenzuron in the cabbage armyworm, Mamestrabrassicae L. J. Pestic. Sci., 9 (1) 19-26.

(23) Miura T., and Takahashi R. M. (1974) Insect development inhibitors; Effects of candidate mosquito control agents on non-target aquatic organism. Environ. Entomol., 3 (4) 631-636.

(24) Ishaaya I., and Horowitz A. R. (1992) Novel phenoxy juvenile hormone analog (pyriproxyfen) suppresses embryogenesis and adult emergence of sweetpotato whitefly (Homoptera: Aleyrodidae). J. Econ. Entomol., 85 (6) 2113-2117.

(25) Mulla M. S. (1995) The future of insect growth regulators in vector control. J. Am. Mosq. Control Assoc., 11 (2) 269-273.

(26) Ascher K. R. S. (1993) Nonconventional insecticidal effects of pesticides available from the Neem tree, Azadirachtaindica. Arch. Insect Biochem. Physiol., 22 (3-4) 433-449.

(27) Asai T. A., Kajihara M., Fukada F., and Makekawa S. (1985) Studies on the mode of action of buprofezin II. Effects on reproduction of the brown planthopper, Nilaparvata lugens Stal (Homoptera: Delphacidae). Appl. Entomol. Zool., 20 (2) 111-117.

(28) Biddinger D. J., Hul L. A., and Mcpheron B. A. (1996) Cross resistance and synergism in azinphosmethyl resistant and susceptible strains of tufted apple bud moth (Lepidoptera: Tortricidae) to various insect growth regulators and avarmectin. J. Econ. Entomol., 89 (2) 274-287.

(29) Moffit H. R., Westigard P. H., Mantey K. D., and Van Debaan H. (1988) Resistance to diflubenzuron in codling moth (Lepidoptera:Tortricidae). J. Econ. Entomol., 81 (6) 1511-1515.

(30) Jennifer Mordue A., Simmonds M. S., Ley S. V., Blaney W. M., Mordue W., Nasiruddin M., and Nisbet A. J. (1998) Actions of azadirachtin, a plant allelochemical, against insects. Pestic. Sci., 54 (3) 277-284.

(31) Bloch G., Borst D. W., Huang Z. Y., Robinson G. E., Cnaani J., and Hefetz A. (2000) Juvenile hormone titers, juvenile hormone biosynthesis, ovarian development and social environment in Bombus terrestris. J. Insect Physiol., 46 (1) 47-57.

(32) Honkakoski P., Jääskeläinen I., Kortelahti M., and Urtti A. (2001) A novel drug-regulated gene expression system based on the nuclear receptor constitutive androstane receptor (CAR). Pharm. Res., 18 (2) 146-150.

(33) Staal G. B. (1975) Insect growth regulators with juvenile hormone activity. Annu. Rev. Entomol., 20 (1) 417-460.

(34) Sun R., Liu C., Zhang H., and Wang Q. (2015) Benzoylurea chitin synthesis inhibitors. J. Agric. Food Chem., 63 (31) 6847-6865.

(35) Bakli D., Kirane-Amrani L., Soltani-Mazouni N., and Soltani N. (2016) Methoxyfenozide, an ecdysteroid agonist insecticide, alters oocyte growth during metamorphosis of Ephestia kuehniella Zeller. Afr. Entomol., 24 (2) 453-459.

(36) Ackova D. G., Kotur-Stevuljevic J., Mishra C. B., Luthra P. M., and Saso L. (2019) Antioxidant Properties of Synthesized Bicyclic Thiazolopyrimidine Derivatives as Possible Therapeutic Agents. Appl. Sci., 9 (1) 113-122.

(37) Linder W., and Brandes W. (1991) Pesticidal Thiazolopyrimidine Derivatives. World Patent Information, 13 (4) 206-208. 
(38) Gilbert L. I., Granger N. A., and Roe R. M. (2000) The juvenile hormones: historical facts and speculations on future research directions. Insect Biochem. Mol. Biol., 30 (8-9) 617-644.

(39) Zimowska G., Miko'lajczyk P., Silhacek D. L., and Oberlander H. (1994) Chitin synthesis in Spodoptera frugiperda wing discs. II. Selective action of chlorfluazuron on wheat germ agglutinin binding and cuticle ultrastructure. Arch. Insect Biochem. Physiol., 27 (2) 89-108.

(40) Zitnanova I., Adams M. E., and Zitnan D. (2001) Dual ecdysteroid action on the epitracheal glands and central nervous system preceding ecdysis of Manduca sexta. J. Exp. Biol., 204 (20) 3483-3495.

(41) Wellinga K., Mulder R., and Dallen J. V. (1973) Synthesis and laboratory evaluation of 1-(2,6disubtitutedbenzoyl)-3-phenylureas, a new class of insecticides. I. 1-(2,5-Dichlorobenzoyl)-3phenylureas. J. Agric. Food Chem., 21 (3) 348-354.

(42) Kolb S., Mondésert O., Goddard M. L., Jullien D., Villoutreix B. O., Ducommun B., Garbay C., and Braud E. (2009) Development of novel thiazolopyrimidines as CDC25B phosphatase inhibitors. Chem Med Chem, 4 (4) 633-648.

(43) Dhadialla T. S., Carlson G. R., and Le D. P. (1998) New insecticides with ecdysteroidal and juvenile hormone activity. Annu. Rev. Entomol., 43 (1) 545-569.

(44) Ishaaya I., Yablonski S., and Horowitz A. R. (1995) Comparative toxicology of two ecdysteroid agonists, RH-2485 and RH-5992, on susceptible and pyrethroid resistant strains of the Egyptian cotton leafworm, Spodoptera littoralis. Phytoparasitica, 23 (2) 139-145.

(45) Toya T., Fukasawa H., Masui A., and Endo Y. (2002) Potent and selective partial ecdysone agonist activity of chromafenozide in sfg cells. Biochem. Biophys. Res. Comm., 292 (4) 1087-1091.

(46) Ahmed M., Younis O., Orabi E. A., Sayed A. M., Kamal El-Dean A. M., Hassanien R., Davis R. L., Tsutsumi O., and Tolba M. S. (2020) Synthesis of novel thienopyrimidines as biocompatible chromophores with aggregation-induced emission sensitive to molecular aggregation. ACS Omega, 5 (46) 29988-30000.

(47) Oikawa N., Nakagawa Y., Nishimura K., Ueno T., and Fujita T. (1994) Quantitative structureactivity analysis of larvicidal 1-(substituted benzoyl)-2-benzoyl1-tert-butylhydrazines against Chilo suppressalis. Pestic Sci., 41 (2) 139-148.

(48) Norland R. L., and Mulla M. S. (1975) Impact of altosid on selected member of an aquatic ecosystem. Environ. Entomol., 4 (1) 145-152.

(49) Cohen E. (2001) Chitin synthesis and inhibition: A revisit. Pest Manag. Sci., 57 (10) 946-950.

(50) Mikołajczyk P., Oberlander H., Silhacek D. L., Ishaaya I., and Shaaya E. (1994) Chitin synthesis in Spodoptera frugiperda wing imaginal discs: I. Chlorfluazuron, diflubenzuron, and teflubenzuron inhibit incorporation but not uptake of [14C] N-acetyl-D-glucosamine. Arch. Insect Biochem. Physiol., 25 (3) 245-258.

(51) Qian X. H. (1999) Quantitative studies on structure-activity relationship of sulfonylurea and benzoylphenylurea type pesticides and their substituents' bioisosterism using synthons' activity contribution. J. Agric. Food Chem., 47 (10) 4415-4418.

(52) Sukach V. A., Tkachuk V. M., Rusanov E. B., Roschenthaler G. V., and Vovk M. V. (2012) Heterocyclization of $\mathrm{N}$-(1-chloro-2,2,2-trifluoro ethylidene)carbamates with $\beta$-enamino esters-a novel synthetic strategy to functionalized trifluoromethylated pyrimidines. Tetrahedron, 68 (40) 8408-15.

(53) Gondkar A. S., Deshmukh V. K., and Chaudhari S. R. (2013) Synthesis, characterization and in vitro antiinflammatory activity of some substituted 1,2,3,4 tetrahydropyrimidine derivatives. Drug. invent. Today, 5 (3) 175-81.

(54) Mohamed A. M., Amr A. E. G., Alsharari M. A., Al-Qalawi H. R. M., Germoush M. O., and AlOmar M. A. (2011) Anticancer activities of some new synthesized thiazolo[3,2-a]pyrido[4,3d]pyrimidine derivatives. Am. J. Biochem. Biotechnol., 7 (2) 43-54.

(55) Speziale A. J., Smith L. R., and Fedder J. E. (1965) The reaction of oxalyl chloride with amides. iv. Synthesis of acyl isocyanates. J. Org. Chem., 30 (12) 4306-4307.

(56) Tecle B., Ruzo L. O., and Casida J. E. (1988) Radiosynthesis of [benzoyl3,4,5-3H]diflubenzuron by a route applicable to other high-potency Insect Growth Regulators. J. Agric. Food Chem., 36 (1) 178-180. 
(57) Kopec S. (1922) Studies on the necessity of the brain for the inception of insect metamorphosis. Biol. Bull., 42 (6) 323-342.

(58) Hammam A. G., El-Salam O. I. A., Mohamed A. M., and Hafez N. A. (2005) Novel fluoro substituted benzo[o]pyran with anti-lung cancer activity. Ind. J. Chem., 44 (9) 1887-1893.

(59) Cai D., Zhang Z.-H., Chen Y., Yan X.-J., Zou L.-J., Wang Y.-X., and Liu X.-Q. (2015) Synthesis, antibacterial and antitubercular activities of some $5 \mathrm{H}$-thiazolo[3,2-a]pyrimidin-5-ones and sulfonic acid derivative. Molecules, 20 (9) 16419-16434.

(60) Wichmann J., Adam G., Kolczewski S., Mutel V., and Woltering T. (1999) Structure-activity relationships of substituted $5 \mathrm{H}$-thiazolo[3,2-a]pyrimidines as group 2 metabotropic glutamate receptor antagonists. Bioorg. Med. Chem. Lett., 9 (11) 1573-1576.

(61) Williams C. M. (1967) The juvenile hormone. II. Its role in the endocrine control of molting, pupation, and adult development in the Cecropia silkworm. Biol. Bull., 121 (3) 572-585.

(62) Al-Omary F. A., Hassan G. S., El-Messery S. M., and ElSubbagh H. I. (2012) Substituted thiazoles V. Synthesis and antitumor activity of novel thiazolo[2,3-b]quinazoline and pyrido[4,3-d] thiazolo[3,2-a] pyrimidine analogues. Eur. J. Med. Chem., 47 (2012) 65-72.

(63) Aouf C., Nouailhas H., Fache M., Caillol S., Boutevin B., and Fulcrand H. (2013) Multifunctionalization of gallic acid. Synthesis of a novel bio-based epoxy resin. Eur. Polym. J., 49 (6) $1185-1195$.

(64) Yildırım A. B., Mutlu E., and Yıldırım M. (2018) Cytotoxic Effects of Thiazolo[3,2-C]Pyrimidines Against Mcf-7 And Hepg2/C3a Carcinoma Cell Lines. Hacet. J. Biol. Chem., 2 (46) 237-246.

(65) Guizzunti G., Brady T. P., Malhotra V., and Theodorakis E. A. (2016) Chemical Analysis of Norrisolide-Induced Golgi Vesiculation. J. Am. Chem. Soc., 128 (13) 4190-4191.

(66) Konkar A. A., Zhu Z., and Granneman J. G. (2000) Aryloxypropanolamine and catecholamine ligand interactions with the $\beta 1$-adrenergic receptor: evidence for interaction with distinct conformations of $\beta 1$-adrenergic receptors. J. Pharmacol. Exp. Ther., 294 (3) 923-932.

(67) Amr A.-E.-G., Maigali S. S., and Abdulla M. M. (2008) Synthesis, and analgesic and antiparkinsonian activities of thiopyrimidine, pyrane, pyrazoline, and thiazolopyrimidine derivatives from 2-chloro-6-ethoxy-4-acetylpyridine. Mon. Chem., 139 (11) 1409-1415.

(68) Jovanovic S., Vico-Stevanovic M., Ugljesic-Kilibarda D., Popadic D., Simic S., and Dzeletovic D. (2006) Catalysis in the alkylation reaction of 1-naphthol with epichlorohydrin. J. Serb. Chem. Soc., 71 (8-9) 867-877.

(69) Bukowska A., Bukowski W., and Mossety-Leszczak B. (1999) Synthesis of glycidyl esters. $J$. Chem. Technol. Biotechnol., 74 (12) 1145-1148.

(70) Tanaka Y., and Kakiuchi H. (1967) Glycidyl Esters of Aromatic Acids. J. Macromol. Sci. Part A Pure Appl. Chem., 1 (8) 1469-1485.

(71) Lebsack A. D., Branstetter B. J., Hack M. D., Xiao W., Peterson M. L., Nasser N., Maher M. P., Hong A., Bhattacharya A., Kansagara M., Scott B. P., Luo L., Rynberg R., Rizzolio M., and Sandr R. (2009) Identification and synthesis of 2,7-diamino-thiazolo[5,4- $d$ ]pyrimidine derivatives as TRPV1 antagonists. Bioorganic Med. Chem. Lett., 19 (1) 40-46.

(72) Aouf C., Lecomte J., Villeneuve P., Dubreucq E., and Fulcrand H. (2012) Chemo-enzymatic functionalization of gallic and vanillic acids: Synthesis of bio-based epoxy resins prepolymers. Green Chem., 14 (8) 2328-2336.

(73) Wang Z. X., Tu Y., Frohn M., Zhang J. R., and Shi Y. (1997) An Efficient Catalytic Asymmetric Epoxidation Method. J. Am. Chem. Soc., 119 (46) 11224-11235.

(74) Curci R., Fiorentino M., Troisi L., Edwards J.O., and Pater, R. H. (1980) Epoxidation of alkenes by dioxirane intermediates generated in the reaction of potassium caroate with ketones. J. Org. Chem., 45 (23) 4758-4760.

(75) Yang D., Wong M. K., and Yip Y. C. (1995) Epoxidation of Olefins Using Methyl(trifluoromethyl)dioxirane Generated in Situ. J. Org. Chem., 60 (12) 3887-3889.

(76) Kambe S., Saito K., Kishi H., Sakurai A., and Midorikawa H. (1979) A One-Step Synthesis of 4Oxo-2-thioxopyrimidine Derivatives by the Ternary Condensation of Ethyl Cyanoacetate, Aldehydes, and Thiourea. Synthesis, 1979 (04) 287-289. 
(77) Fache M., Auvergne R., Boutevin B., and Caillol S. (2015) New vanillin-derived diepoxy monomers for the synthesis of biobased thermosets. Eur. Polym. J., 67 (2014) 527-538.

(78) Fache M., Monteremal C., Boutevin B., and Caillol S. (2015) Amine hardeners and epoxy crosslinker from aromatic renewable resources. Eur. Polym. J., 73 (2015) 344-362.

(79) Fache M., Viola A., Auvergne R., Boutevin B., and Caillol S. (2015) Biobased epoxy thermosets from vanillin-derived oligomers. Eur. Polym. J., 68 (2015) 526-535.

(80) Laurichesse S., and Averous L. (2014) Chemical modification of lignins: Towards biobased polymers. Prog. Polym. Sci., 39 (7) 1266-1290.

(81) Duva A., Lange H., Lawoko M., and Crestini C. (2015) Reversible crosslinking of lignin via the furan-maleimide Diels-Alder reaction. Green Chem., 17 (11) 4991-5000.

(82) Oliveira F. D., Ramires E. C., Frollini E., and Belgacem M. N. (2015) Lignopolyurethanic materials based on oxypropylated sodium lignosulfonate and castor oil blends. Ind. Crops Prod., 73 (2015) 77-86.

(83) Arbenz A., and Averous L. (2015) Chemical modification of tannins to elaborate aromatic biobased macromolecular architectures. Green Chem., 17 (5) 2626-2646.

(84) Eghbaliferiz S., and Iranshahi M. (2016) Prooxidant Activity of Polyphenols, Flavonoids, Anthocyanins and Carotenoids: Updated Review of Mechanisms and Catalyzing Metals. Phytother. Res., 30 (9) 1379-1391.

(85) Mubofu E. B. (2016) From cashew nut shell wastes to high value chemicals. Pure Appl. Chem., 88 (1-2) 17-27.

(86) Zhu H., Luo W., Ciesielski P. N., Fang Z., Zhu J. Y., Henriksson G., Himmel M. E., and Hu L. (2016) Wood-derived materials for green electronics, biological devices, and energy applications. Chem. Rev., 116 (16) 9305-9374.

(87) Moreau C., Belgacem M. N., and Gandini A. (2004) Recent catalytic advances in the chemistry of substituted furans from carbohydrates and in the ensuing polymers. Top. Catal., 27 (1) 11-30.

(88) Wool R., and Sun X. S. (2005) Bio-Based Polymers and Composites, 1st Ed, Academic Press, Cambridge, MA, USA.

(89) Garrison M. D., and Harvey B. G. (2016) Bio-based hydrophobic epoxy-amine networks derived from renewable terpenoids. J. Appl. Polym. Sci., 133 (45) 1-12.

(90) Harvey B. G., Guenthner A. J., Koontz T. A., Storch P. J., Reams J. T., and Groshens T. J. (2016) Sustainable hydrophobic thermosetting resins and polycarbonates from turpentine. Green Chem., 18 (8) 2416-2423.

(91) Qin J., Liu H., Zhang P., Wolcott M., and Zhang J. (2016) Use of eugenol and rosin as feedstocks for biobased epoxy resins and study of curing and performance properties. Polym. Int., 63 (4) 760 765.

(92) Maiorana A., Reano A. F., Centore R., Grimaldi M., Balaguer P., Allais F., and Gross R. A. (2016) Structure property relationships of biobased n-alkyl bisferulate epoxy resins. Green Chem., 18 (18) 4961-4973.

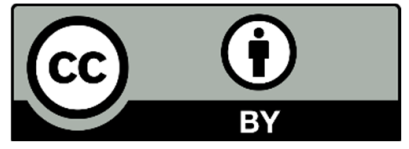

(C) 2020 by the authors; licensee Growing Science, Canada. This is an open access article distributed under the terms and conditions of the Creative Commons Attribution (CC-BY) license (http://creativecommons.org/licenses/by/4.0/). 